\title{
Antimicrobial Properties of Copper Nanoparticles and Amino Acid Chelated Copper Nanoparticles Produced by Using a Soya Extract
}

\author{
I. DeAlba-Montero, ${ }^{1,2}$ Jesús Guajardo-Pacheco, ${ }^{3}$ Elpidio Morales-Sánchez, ${ }^{4}$ \\ Rene Araujo-Martínez, ${ }^{5}$ G. M. Loredo-Becerra, ${ }^{5}$ Gabriel-Alejandro Martínez-Castañón, ${ }^{3}$ \\ Facundo Ruiz, ${ }^{2}$ and M. E. Compeán Jasso ${ }^{2}$ \\ ${ }^{1}$ Doctorado Institucional en Ingeniería y Ciencia de Materiales, Universidad Autónoma de San Luis Potosí, \\ San Luis Potosí, SLP, Mexico \\ ${ }^{2}$ Facultad de Ciencias, Universidad Autónoma de San Luis Potosí, San Luis Potosí, SLP, Mexico \\ ${ }^{3}$ Facultad de Estomatología, Universidad Autónoma de San Luis Potosí, San Luis Potosí, SLP, Mexico \\ ${ }^{4}$ Departamento Físico Matemático, Universidad Autónoma de San Luis Potosí, San Luis Potosí, SLP, Mexico \\ ${ }^{5}$ Coordinación para la Innovación y Aplicación de la Ciencia y Tecnología, Universidad Autónoma de San Luis Potosí, \\ San Luis Potosí, SLP, Mexico
}

Correspondence should be addressed to M. E. Compeán Jasso; martha.compean@gmail.com

Received 15 November 2016; Accepted 10 January 2017; Published 13 February 2017

Academic Editor: Claudio Pettinari

Copyright ( 2017 I. DeAlba-Montero et al. This is an open access article distributed under the Creative Commons Attribution License, which permits unrestricted use, distribution, and reproduction in any medium, provided the original work is properly cited.

\begin{abstract}
This paper reports a comparison of the antibacterial properties of copper-amino acids chelates and copper nanoparticles against Escherichia coli, Staphylococcus aureus, and Enterococcus faecalis. These copper-amino acids chelates were synthesized by using a soybean aqueous extract and copper nanoparticles were produced using as a starting material the copper-amino acids chelates species. The antibacterial activity of the samples was evaluated by using the standard microdilution method (CLSI M100-S25 January 2015). In the antibacterial activity assays copper ions and copper-EDTA chelates were included as references, so that copperamino acids chelates can be particularly suitable for acting as an antibacterial agent, so they are excellent candidates for specific applications. Additionally, to confirm the antimicrobial mechanism on bacterial cells, MTT assay (3-[4,5-dimethylthiazol-2-yl]2,5-diphenyltetrazolium bromide) was carried out. A significant enhanced antimicrobial activity and a specific strain were found for copper chelates over E. faecalis. Its results would eventually lead to better utilization of copper-amino acids chelate for specific application where copper nanoparticles can be not used.
\end{abstract}

\section{Introduction}

It is well known that the copper has a wide activity against bacteria and fungi [1-4]. Due to the development of antibiotic resistance and the surging of infectious diseases, a lot of researchers are searching for new antibacterial agents [5-11].

Although copper is one of the most widely used materials in various applications, its nanosynthesis requires some special care because of their high holding to rust. Compared to gold and silver, copper is extremely sensitive to air, and copper oxides phases are thermodynamically more stable.
Therefore, the formation of an oxide layer on the surface of the copper nanoparticles is inevitably causing a marked decrease of its antibacterial properties [12-14].

In the last few years, several organics copper complexes of $\mathrm{Ni}, \mathrm{Cu}$, and $\mathrm{Co}$ have been tested for their antibacterial and antitumor properties. Their mode of action is probably the binding of amino acids and metals ions, which is likely to leave some potential donors of free atoms and enhance the biological activity [13, 15-17].

Chelates are highly stable products capable of maintaining the surrounded metal ions from an organic molecule 
(chelating agent); so its precipitation as insoluble hydroxides should be avoided with the care of the storage $[15,18]$.

We have previously reported about a soybean aqueous extract mediated synthesis of very stable copper nanoparticles; in this work we report the antibacterial activity of copper nanoparticles and copper chelated species that are an intermediate step between ion copper and copper nanoparticles [19]. The main objective was to compare the antibacterial properties of different species of copper, such as copper nanoparticles and copper chelates. Such comparative study would reveal strain specificities and would eventually lead to better utilization of copper-amino acids chelate for specific application where copper nanoparticles could be not used.

\section{Materials and Methods}

2.1. Reagents. Textured soy was purchased in a local natural products supermarket; sodium hydroxide $(\mathrm{NaOH})$ and copper sulfate $\left(\mathrm{CuSO}_{4} \cdot 5 \mathrm{H}_{2} \mathrm{O}\right)$ of Sigma-Aldrich were used without any further purification. Milli-Q water $(18.2 \Omega)$ was used throughout the experiment; and the synthesis reagents are phosphate buffer $\mathrm{Na}_{2} \mathrm{HPO}_{4}$ and $\mathrm{KH}_{2} \mathrm{PO}_{4}$ (Fermont), Mueller-Hinton broth (BD Difco), sodium chloride $(\mathrm{NaCl}$, CTR Scientific), and Kit MTT 3-[4,5-dimethylthiazol-2-yl]2,5-diphenyl tetrazolium bromide (Sigma-Aldrich).

2.2. Characterization. Optical absorption spectra were obtained with an Ocean Optics S2000-UV-Vis system, Transmission Electron Microscopy (TEM) images at $100 \mathrm{kV}$ were carried out using a JEOL-1230, Thermogravimetric Analysis (TGA) was made, and the average particle size was measured with a Dynamic Light Scattering Nanosizer (DLS). Infrared spectroscopy (FTIR) was made with an IR Affinity-1.

2.3. Experimental Method. Six samples were prepared to compare the bactericidal activity; the samples with copper were synthesized with a concentration of $40 \mathrm{mM}$. The syntheses are described as follows:

(i) Soybeans extract: the solution was prepared by heating to boiling point $100 \mathrm{~mL}$ of deionized water with $3 \mathrm{~g}$ of textured soya for $10 \mathrm{~min}$; the fiber was then separated by filtration.

(ii) Ionic solution of $\mathrm{Cu}^{2+}$ species: this solution was prepared adding $\mathrm{CuSO}_{4}$ in deionized water.

(iii) Copper-soybean extract chelates: they were synthetized according to the method previously reported by Guajardo-Pacheco et al. [19]. A soybean extract solution was prepared, as described above; after that, $1 \mathrm{gr}$ of $\mathrm{CuSO}_{4} \cdot 5 \mathrm{H}_{2} \mathrm{O}$ was added and mixed for $15 \mathrm{~min}$ in magnetic stirring; the $\mathrm{pH}$ was adjusted to 7 using a $1 \mathrm{M}$ solution of sodium hydroxide.

(iv) Colloidal dispersion of copper nanoparticles: the particles were prepared in the aqueous phase by a chemical reduction of copper chelate complex solution using sodium borohydride as reducer. $100 \mathrm{~mL}$ solutions of copper chelate complex were purged with $\mathrm{N}_{2}$ gas for $10 \mathrm{~min}$ to remove the dissolved oxygen;
$1 \mathrm{~mL}$ of aqueous solution of sodium borohydride $(0.1 \mathrm{M})$ was then added to it drop-wise under constant stirring. The solution turned into a black color on the complete addition of the reducing agent, denoting the formation of copper nanoparticles. The nanoparticles were washed repeatedly with ethylic alcohol [19].

(v) EDTA-copper chelate: for EDTA chelated copper solution, 1 gr of $\mathrm{CuSO}_{4} \cdot 5 \mathrm{H}_{2} \mathrm{O}$ and $1 \mathrm{gr}$ of EDTA were mixed in $100 \mathrm{~mL}$ of deionized water. The Cu/EDTA ratio was calculated previously by 11.68 .

2.4. Antimicrobial Test. The antimicrobial activity of the chelates was tested using the standard microdilution method, which determines the minimum inhibitory concentration (MIC) and the minimum bactericide concentration (MBC), leading to the inhibition of bacterial growth (CLSI M100S25 January 2015). The strains tested were Escherichia coli (ATCC 25922), Staphylococcus aureus (ATCC 29213), and Enterococcus faecalis (ATCC 29212). The bacterial concentration was standardized to an optical density of 0.2 at $568 \mathrm{~nm}$ (approximately $1 \times 10^{8} \mathrm{CFU} / \mathrm{mL}$ ) using the McFarland scale. The chelates in dispersion were diluted with $50 \mu \mathrm{L}$ of MuellerHinton broth and $50 \mu \mathrm{L}$ of phosphate buffer inoculated with the tested strains at a concentration of $1 \times 10^{5} \mathrm{CFU} / \mathrm{mL}$ was grown for $24 \mathrm{~h}$ at $35 \pm 1^{\circ} \mathrm{C}[20]$.

2.5. MTT Assay. The MTT assay was used for measuring the proliferation of bacterial cells. Bacterial cells $\left(10^{5} \mathrm{CFU} / \mathrm{mL}\right)$ were incubated into Mueller-Hinton broth at $50 \mu \mathrm{L}$ per well in 96-well microtiter plates. Threefold serial dilutions of copperamino acids chelate were added to wells containing bacterial cells. After $24 \mathrm{~h}$ of incubation at $37^{\circ} \mathrm{C}$, each concentration was tested in triplicate. 24 hours later, $10 \mu \mathrm{L}$ of the MTT $(5 \mu \mathrm{L} / \mathrm{mL})$ reagent was added to each well and the plates were incubated for $4 \mathrm{~h}$ at $37^{\circ} \mathrm{C}$. Then, DMSO $(100 \mu \mathrm{L})$ was added to finish the reaction; the plate was shaken gently to redissolve the crystals formed. The absorbance was read at $490 \mathrm{~nm}$ wavelength by a Microplate Reader (Bio-Rad Laboratories) spectrophotometer. The results were expressed as the inhibition ratio of cell increase calculated as $[(A-$ $B) / A] * 100 \%$, in which $A$ and $B$ represent the average of live bacteria of the control and samples, respectively [21].

\section{Results and Discussion}

Figure 1(a) shows UV-Vis absorption spectra of the copper ions solution and Figure 1(b) copper-soybeans extract solution. It is possible to observe the typical wide band associated to copper free ions in the range between 650 and $1000 \mathrm{~nm}$ with a maximum at approximately $800 \mathrm{~nm}$ [22]. In Figure 1(b) this band disappears indicating the depletion of the copper free ions and formation of a copper-soya extract complex. The band in the range between 400 and $550 \mathrm{~nm}$ has been ascribed to soybeans extract.

Figure 2 shows the absorption infrared spectrum of the copper-soybean extract solution. There can be seen bands in the range from 400 to $500 \mathrm{~cm}^{-1}$ corresponding to the formation of the copper chelate, the band at $457 \mathrm{~cm}^{-1}$ is 


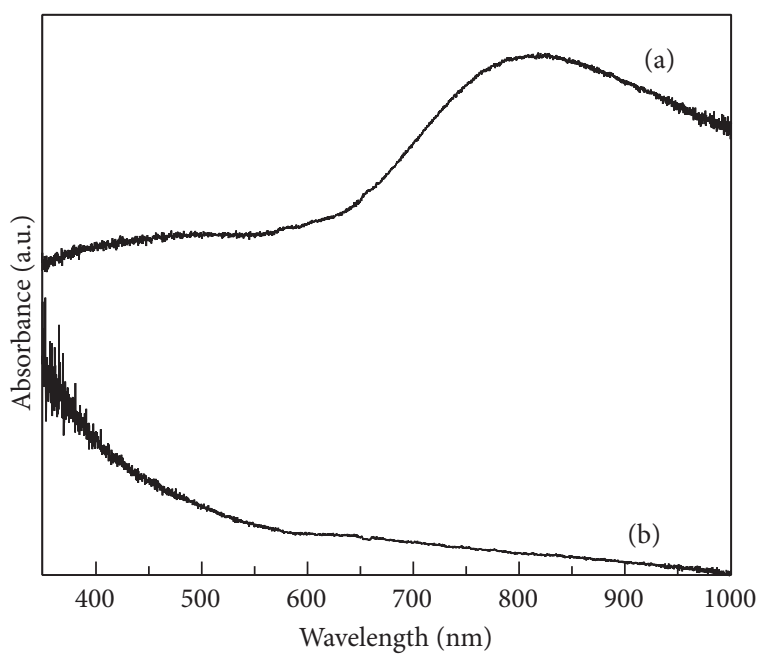

Figure 1: UV-Vis spectrum of (a) ionic solution of copper and (b) copper-amino acids chelate.

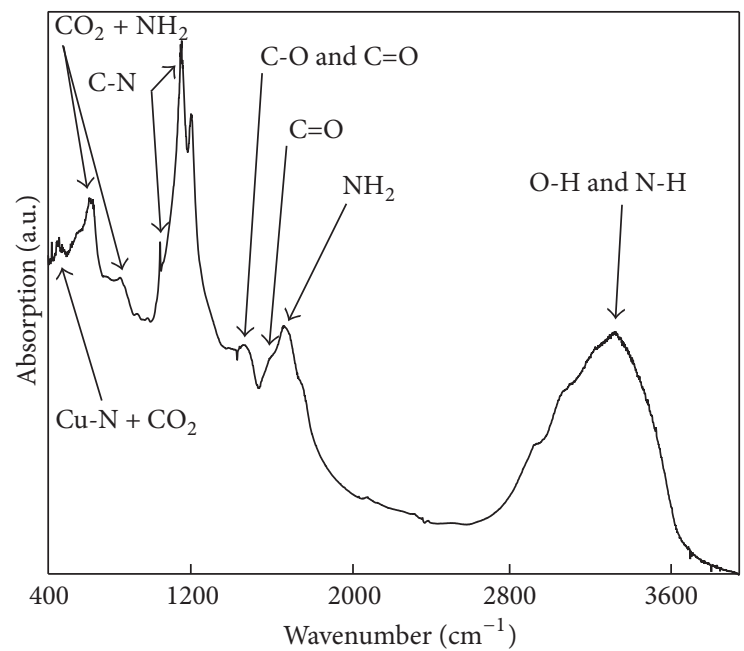

FIGURE 2: Infrared absorption spectra of copper-amino acids chelate.

assigned to the contribution of the $\mathrm{Cu}-\mathrm{N}$ symmetric vibration and $\mathrm{CO}_{2}$ wagging, and the bands at $614 \mathrm{~cm}^{-1}$ and $773 \mathrm{~cm}^{-1}$ can be ascribed to the contribution of $\mathrm{CO}_{2}$ rocking and $\mathrm{NH}_{2}$ rocking due to complex with amino acids; from 1000 to $1100 \mathrm{~cm}^{-1}$ are the $\mathrm{C}-\mathrm{N}$ vibrations. The peaks of $\nu(\mathrm{C}-\mathrm{O})$ and $\nu(\mathrm{C}=\mathrm{O})$ at $1421 \mathrm{~cm}^{-1}, 1580 \mathrm{~cm}^{-1}$, and $1626 \mathrm{~cm}^{-1}$ are the contribution of $v(\mathrm{C}=\mathrm{O})$ and $\mathrm{NH}_{2}$ scissoring, respectively. The range from 3290 to $3390 \mathrm{~cm}^{-1}$ corresponds to $\mathrm{O}-\mathrm{H}$ and $\mathrm{N}-\mathrm{H}$ vibrations. All of these vibrations modes confirm the copper-amino acid complex formation [23]; it is well known that the soybean is rich in proteins content, of which the $95 \%$ of the total protein is called soluble protein, and approximately $16 \%$ is attributed to the Nitrogen presence $[24,25]$, favoring the copper-amino acids chelates formation as can be seen in the infrared absorption spectra.

Figure 3 shows the UV-Vis absorption spectrum of (a) EDTA starting solution, where a wide band in the range of

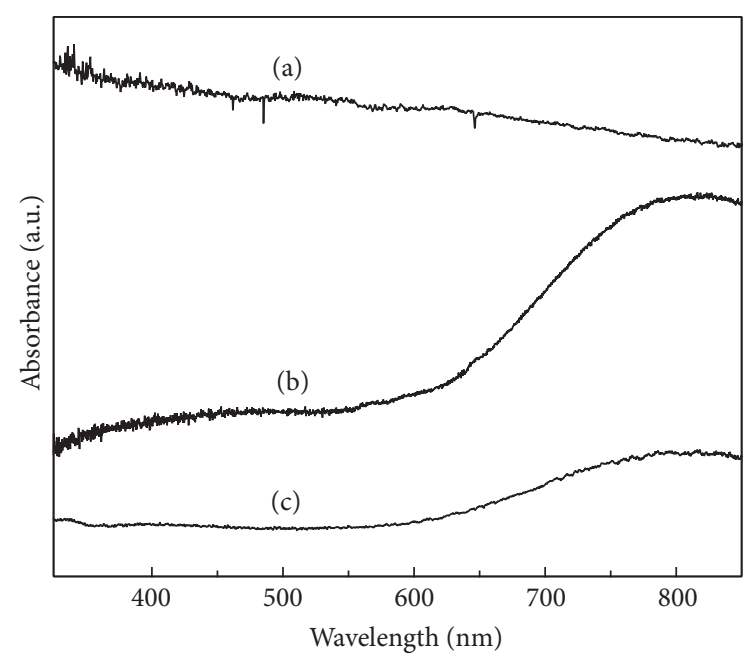

FIGURE 3: UV-Vis spectrum of (a) EDTA solution, (b) ionic solution of copper, and (c) EDTA-copper chelate.

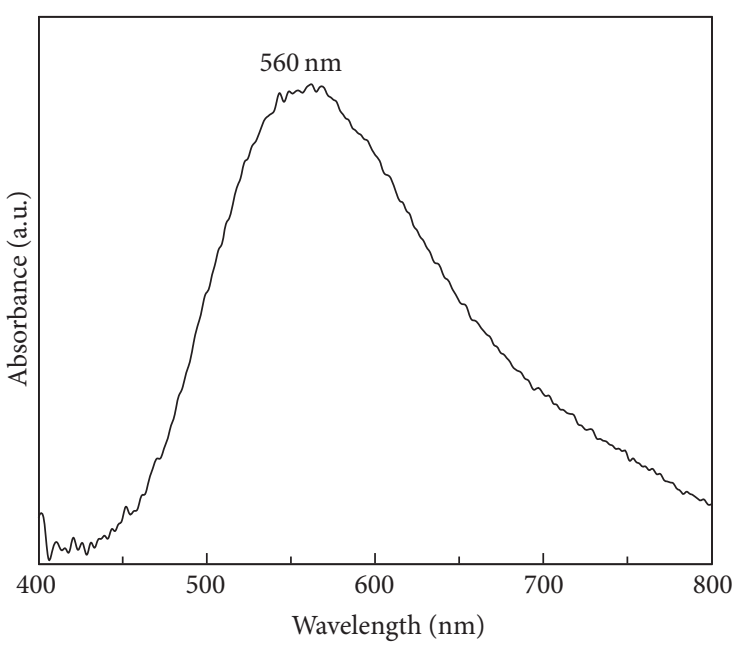

FIGURE 4: UV-Vis of copper nanoparticles sample.

400 to $900 \mathrm{~nm}$ can be observed, and (b) ionic copper solution with its typical band wide range between 400 and $900 \mathrm{~nm}$ and the maximum being approximately at $800 \mathrm{~nm}$. And (c) corresponds to the EDTA-copper chelate sample; as it is possible to see, the maximum of ionic copper band decreases due to the copper free ions depletion and formation of copper chelate with the EDTA; this might represent a proof of chelate formation.

Figure 4 shows the UV-Vis absorption spectrum of the copper nanoparticles sample with a typical absorption plasmon band at approximately $560 \mathrm{~nm}$.

Figure 5 shows a TEM image of copper nanoparticles sample, in which there can be observed that the nanoparticles have quasi-spherical shapes with an average diameter of $5.67 \pm 0.5337 \mathrm{~nm}$ as it can be seen in the histogram, where 169 nanoparticles were measured. The TEM image and the histogram also show a narrow size distribution of the 

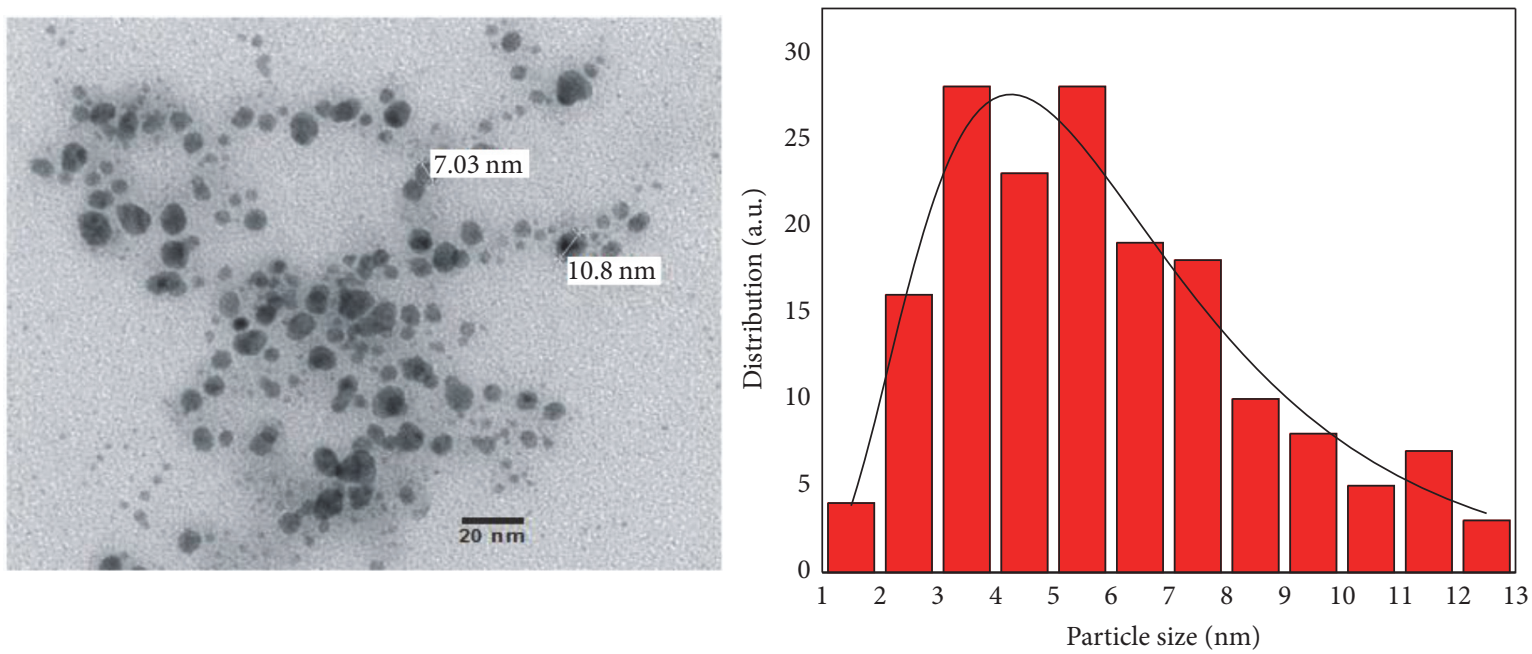

FIGURE 5: TEM image of copper nanoparticles sample and the particle size distribution histogram.

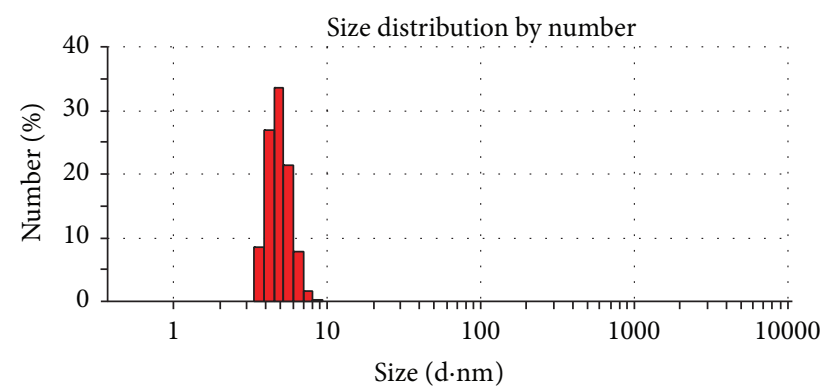

Figure 6: Dynamic Light Scattering measurement of copper nanoparticles sample.

nanoparticles; this could be corroborated by Dynamic Light Scattering measurements (Figure 6).

Figure 6 shows the Dynamic Light Scattering measurement of copper nanoparticles; the average size obtained was of $4.9 \mathrm{~nm}$ with a narrow size distribution.

3.1. Antibacterial Results. MIC values were obtained for the chelates tested against E. coli (ATCC 25922), S. aureus (ATCC 29213), and E. faecalis (ATCC 29212). The results are presented in Table 1, where it can be seen that the copperamino acids chelate sample presents the best antibacterial activity against the three strains tested in comparison with copper ions, copper-EDTA chelate, and copper nanoparticles.

The MIC of the copper nanoparticles and the copperamino acids chelates is lower when it is tested against $E$. faecalis than when tested against E. coli and S. aureus. These results may refer to differences in the cell wall of each strain; the cell wall of Gram-positive strains is wider than the cell wall of Gram-negative strains [26]. In addition, the reported mechanism for the toxicity of copper ions on E. faecalis includes a rapid DNA degradation, followed by a reduction of bacterial respiration; it is also known that copper ions inhibit certain cytochromes in the membrane of E. faecalis by altering the conformation and electron transference of
TABLE 1: Minimum inhibitory concentrations (MIC).

\begin{tabular}{|c|c|c|c|}
\hline \multirow{3}{*}{ Sample } & \multicolumn{3}{|c|}{ MIC copper (mM) } \\
\hline & \multicolumn{3}{|c|}{ Bacterial strains } \\
\hline & $\begin{array}{c}\text { E. coli } \\
\text { (ATCC 25922) }\end{array}$ & $\begin{array}{c}\text { S. aureus } \\
\text { (ATCC 29213) }\end{array}$ & $\begin{array}{c}\text { E. faecalis } \\
\text { (ATCC 29212) }\end{array}$ \\
\hline Soybeans extract & $-^{\mathrm{a}}$ & $-^{\mathrm{a}}$ & $-{ }^{a}$ \\
\hline Ionic solution of $\mathrm{Cu}$ & $20 \pm 0$ & $20 \pm 0$ & $20 \pm 0$ \\
\hline $\begin{array}{l}\text { Copper-amino acids } \\
\text { chelate }\end{array}$ & $10 \pm 0$ & $10 \pm 0$ & $5 \pm 0$ \\
\hline $\begin{array}{l}\text { Copper } \\
\text { nanoparticles }\end{array}$ & $40 \pm 0$ & $40 \pm 0$ & $20 \pm 0$ \\
\hline $\begin{array}{l}\text { EDTA-copper } \\
\text { chelate }\end{array}$ & $20 \pm 0$ & $20 \pm 0$ & $20 \pm 0$ \\
\hline EDTA solution & $40 \pm 0$ & $40 \pm 0$ & $40 \pm 0$ \\
\hline
\end{tabular}

${ }^{\mathrm{a}}$ The antibacterial activity was not found with the $\mathrm{mM}$ concentrations used in this work.

associated reductases [27]. These affectations of copper over E. faecalis could be potentiated with the presence of amino acids in the copper chelate and this could be the reason why $E$. faecalis is more sensitive to copper-amino acids chelate than E. coli and S. aureus.

As for the copper nanoparticles and the EDTA reference there is no significant difference between the MIC results of E. coli and S. aureus.

Figure 7 shows the MICs of copper nanoparticles and copper-amino acids chelate against bacterial strains $E$. faecalis. The serial dilutions of nanoparticles were exposed to bacterial strains, and we can see that the copper-amino acids chelate antimicrobial effect is better than that of the copper nanoparticles; in general, the copper-amino acids chelate showed the highest activity among all the six samples in the three bacteria tested (Table 1 ).

In Figure 8, we can see MTT assay results for the copperamino acids chelate sample; the Inhibition Rate value for E. faecalis is higher compared to E. coli and S. aureus at a 

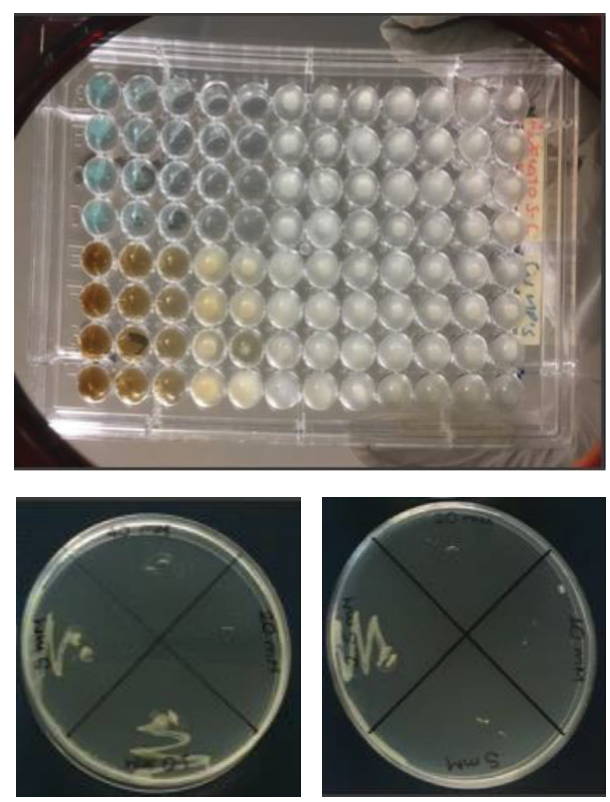

(a) Copper nanoparticles

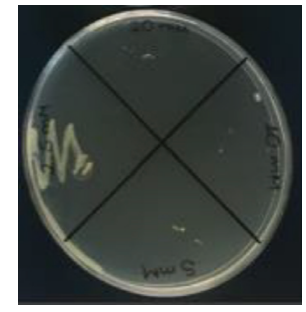

(b) Copper-amino acids chelates

FIGURE 7: MICs of nanoparticles against bacterial strain Enterococcus faecalis. (a) Copper nanoparticles; (b) copper-amino acids chelate.

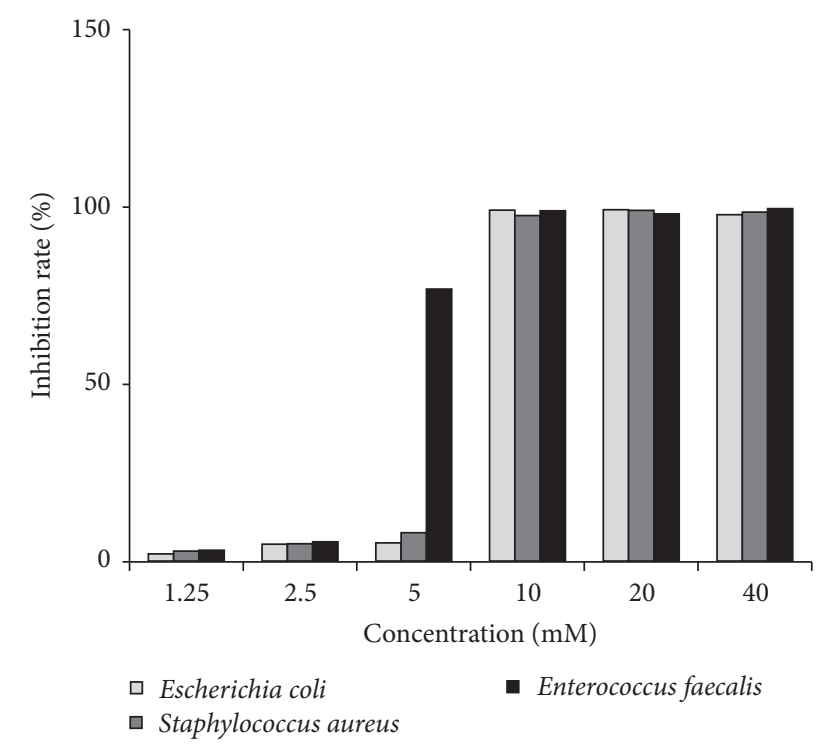

FIGURE 8: Effect of copper-amino acids chelate sample by MTT assay.

concentration of $10 \mathrm{mM}$, representing one order of magnitude smaller compared to the concentrations obtained for the other tested solutions.

\section{Conclusions}

Copper-amino acids chelate was synthetized in aqueous solution and antimicrobial assays, which demonstrates that its strain specificities and enhanced activity are about ten times more effective comparing to the copper nanoparticles and the copper-EDTA chelate, obtaining a better antimicrobial effect against E. faecalis rather than both $E$. coli and $S$. aureus. These results show that copper-soy chelates can be particularly suitable as antibacterial agent candidates for specific application instead of copper nanoparticles.

\section{Competing Interests}

The authors declare that there is no conflict of interests regarding the publication of this paper.

\section{Acknowledgments}

This study was supported by the Consejo Nacional de Ciencia y Tecnología (CONACyT) Grants C005-189530 and CB-2010-01-153675. De Alba-Montero and G. M. LoredoBecerra would like to thank CONACyT for Scholarship nos. 358436 and 401515, respectively. Financial support for the payment of the processing charges was made by Programa para el Desarrollo Profesional Docente para el Tipo Superior (PRODEP 2016).

\section{References}

[1] J. P. Ruparelia, A. K. Chatterjee, S. P. Duttagupta, and S. Mukherji, "Strain specificity in antimicrobial activity of silver and copper nanoparticles," Acta Biomaterialia, vol. 4, no. 3, pp. 707-716, 2008.

[2] C. Cervantes and F. Gutierrez-Corona, "Copper resistance mechanisms in bacteria and fungi," FEMS Microbiology Reviews, vol. 14, no. 2, pp. 121-137, 1994.

[3] S. Silver, "Bacterial silver resistance: molecular biology and uses and misuses of silver compounds," FEMS Microbiology Reviews, vol. 27, no. 2-3, pp. 341-353, 2003.

[4] G. Ren, D. Hu, E. W. C. Cheng, M. A. Vargas-Reus, P. Reip, and R. P. Allaker, "Characterisation of copper oxide nanoparticles for antimicrobial applications," International Journal of Antimicrobial Agents, vol. 33, no. 6, pp. 587-590, 2009.

[5] M. J. Hajipour, K. M. Fromm, A. Akbar Ashkarran et al., "Antibacterial properties of nanoparticles," Trends in Biotechnology, vol. 30, no. 10, pp. 499-511, 2012.

[6] M. Agarwala, B. Choudhury, and R. N. S. Yadav, "Comparative study of antibiofilm activity of copper oxide and iron oxide nanoparticles against multidrug resistant biofilm forming uropathogens," Indian Journal of Microbiology, vol. 54, no. 3, pp. 365-368, 2014.

[7] R. Y. Pelgrift and A. J. Friedman, "Nanotechnology as a therapeutic tool to combat microbial resistance," Advanced Drug Delivery Reviews, vol. 65, no. 13-14, pp. 1803-1815, 2013.

[8] J. R. Morones, J. L. Elechiguerra, A. Camacho et al., "The bactericidal effect of silver nanoparticles," Nanotechnology, vol. 16, no. 10, pp. 2346-2353, 2005.

[9] R. Chakraborty, R. K. Sarkar, A. K. Chatterjee, U. Manju, A. P. Chattopadhyay, and T. Basu, "A simple, fast and costeffective method of synthesis of cupric oxide nanoparticle with promising antibacterial potency: unraveling the biological and chemical modes of action," Biochimica et Biophysica Acta, vol. 1850, no. 4, pp. 845-856, 2015. 
[10] C. Sámano-Valencia, G. A. Martinez-Castanon, F. MartínezGutiérrez et al., "Characterization and biocompatibility of chitosan gels with silver and gold nanoparticles," Journal of Nanomaterials, vol. 2014, Article ID 543419, 11 pages, 2014.

[11] C. Larimer, M. S. Islam, A. Ojha, and I. Nettleship, "Mutation of environmental mycobacteria to resist silver nanoparticles also confers resistance to a common antibiotic," BioMetals, vol. 27, no. 4, pp. 695-702, 2014.

[12] S. Jeong, K. Woo, D. Kim et al., "Controlling the thickness of the surface oxide layer on $\mathrm{Cu}$ nanoparticles for the fabrication of conductive structures by ink-jet printing," Advanced Functional Materials, vol. 18, no. 5, pp. 679-686, 2008.

[13] S. Chen and J. M. Sommers, "Alkanethiolate-protected copper nanoparticles: spectroscopy, electrochemistry, and solid-state morphological evolution," Journal of Physical Chemistry B, vol. 105, no. 37, pp. 8816-8820, 2001.

[14] C. Salzemann, I. Lisiecki, A. Brioude, J. Urban, and M.-P. Pileni, "Collections of copper nanocrystals characterized by different sizes and shapes: optical response of these nanoobjects," Journal of Physical Chemistry B, vol. 108, no. 35, pp. 13242-13248, 2004.

[15] J. J. Lucena, "El empleo de complejantes y quelatos en la fertilización de micronutrientes," Revista Ceres, vol. 56, no. 4, pp. 527-535, 2009.

[16] T. Ganz, "Defensins and other antimicrobial peptides: a historical perspective and an update," Combinatorial Chemistry \& High Throughput Screening, vol. 8, no. 3, pp. 209-217, 2005.

[17] F. D. Silva, C. A. Rezende, D. C. P. Rossi et al., "Structure and mode of action of microplusin, a copper II-chelating antimicrobial peptide from the cattle tick Rhipicephalus (Boophilus) microplus," The Journal of Biological Chemistry, vol. 284, no. 50, pp. 34735-34746, 2009.

[18] F. Basolo and R. Johnson, Química de los Compuestos de Coordinación, Reverté, Bellvei, España, 1980.

[19] M. J. Guajardo-Pacheco, J. E. Morales-Sánchez, J. GonzálezHernández, and F. Ruiz, "Synthesis of copper nanoparticles using soybeans as a chelant agent," Materials Letters, vol. 64, no. 12, pp. 1361-1364, 2010.

[20] P. A. Wayne, "CLSI. Performance Standards for Antimicrobial Susceptibility Testing; Twenty-Fifth Informational Supplement," CLSI Document M100-S25, Clinical and Laboratory Standards Institute, 2015.

[21] X. Wang, Y. C. Wu, S. P. Xia, Y. Gao, and C. X. Li, "Inquiring into the method of counting live germ with MTT," Journal of Luzhou Medical College, vol. 25, pp. 291-293, 2002.

[22] P. De Vreese, N. R. Brooks, K. Van Hecke et al., "Speciation of copper(II) complexes in an ionic liquid based on choline chloride and in choline chloride/water mixtures," Inorganic Chemistry, vol. 51, no. 9, pp. 4972-4981, 2012.

[23] A. Cuevas, I. Viera, M. H. Torre, E. Kremer, S. B. Etcheverry, and E. J. Baran, "Infrared spectra of the Copper(II) complexes of amino acids with hydrophobic residues," Acta Farmaceutica Bonaerense, vol. 17, no. 3, pp. 213-218, 1998.

[24] K. A. Kuiken and C. M. Lyman, "Essential amino acid composition of soy bean meals prepared from twenty strains of soy beans," The Journal of Biological Chemistry, vol. 177, pp. 29-36, 1948.

[25] C. H. Van Etten, J. E. Hubbard, J. M. Mallan, A. K. Smith, and C. W. Blessin, "Amino acid composition of soybean protein fractions," Agricultural and Food Chemistry, vol. 7, no. 2, pp.129131, 1959.

[26] J. Thiel, L. Pakstis, S. Buzby et al., "Antibacterial properties of silver-doped titania," Small, vol. 3, no. 5, pp. 799-803, 2007.
[27] S. L. Warnes and C. W. Keevil, "Mechanism of copper surface toxicity in vancomycin-resistant enterococci following wet or dry surface contact," Applied and Environmental Microbiology, vol. 77, no. 17, pp. 6049-6059, 2011. 

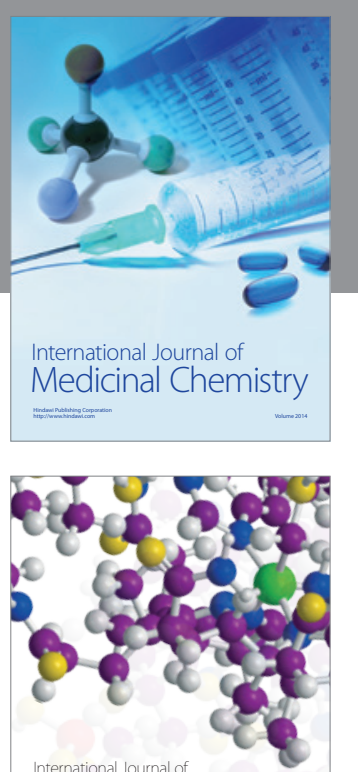

Carbohydrate Chemistry

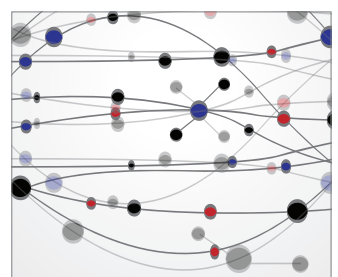

The Scientific World Journal
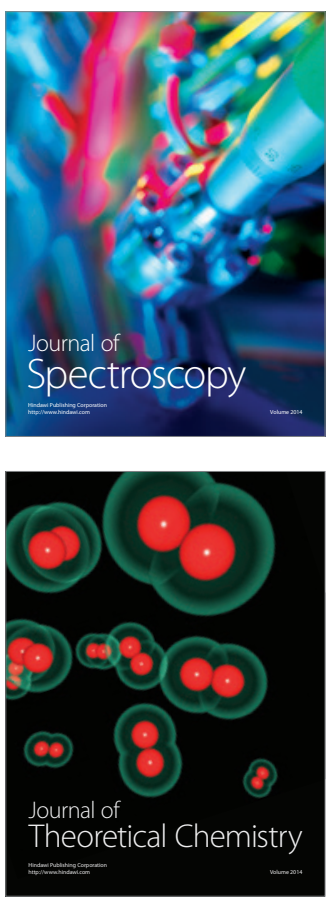
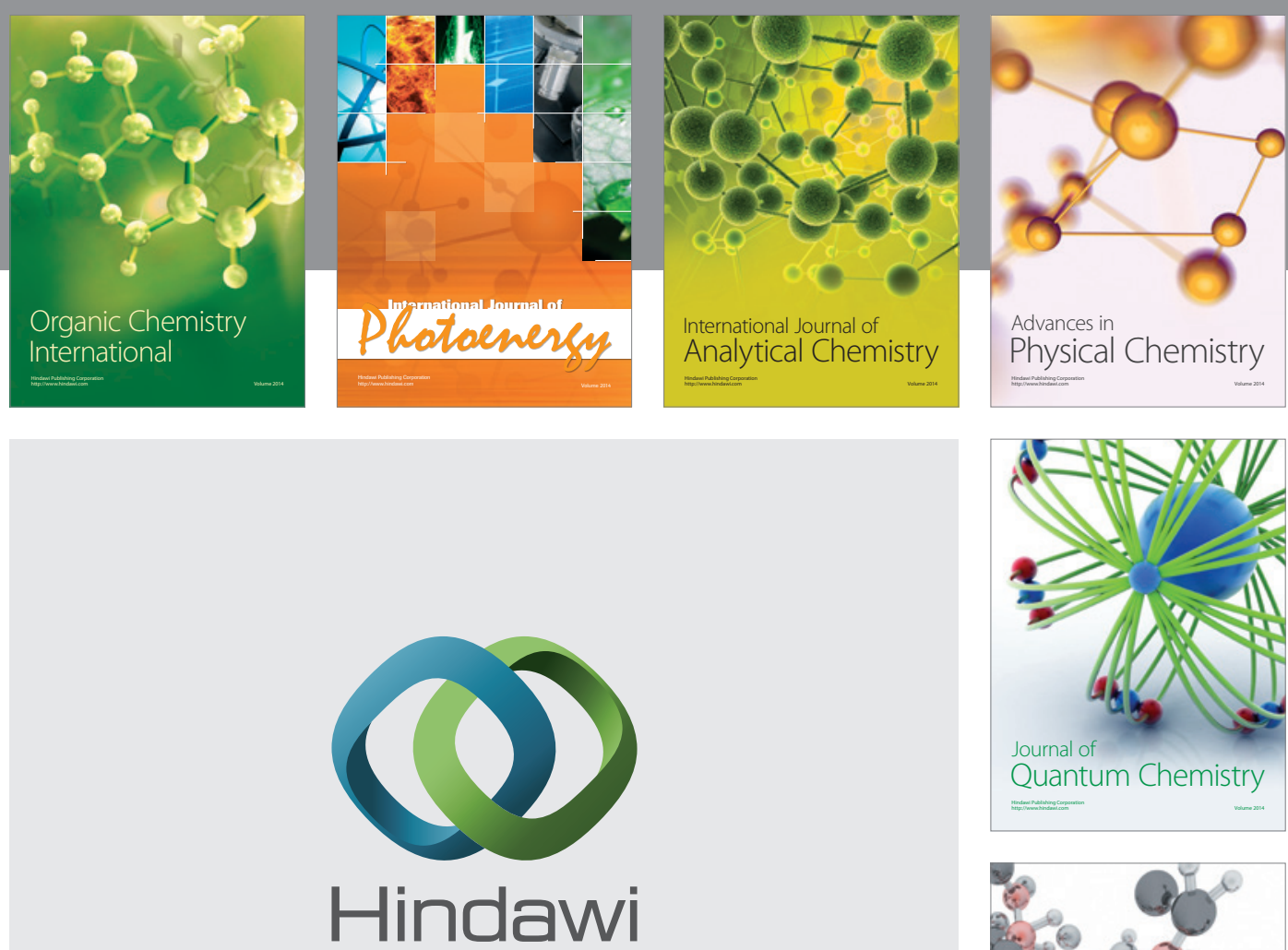

Submit your manuscripts at

https://www.hindawi.com

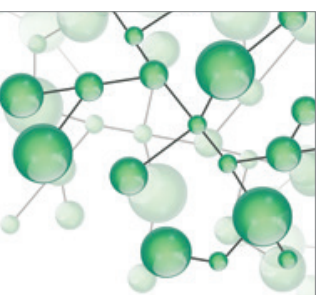

International Journal of

Inorganic Chemistry
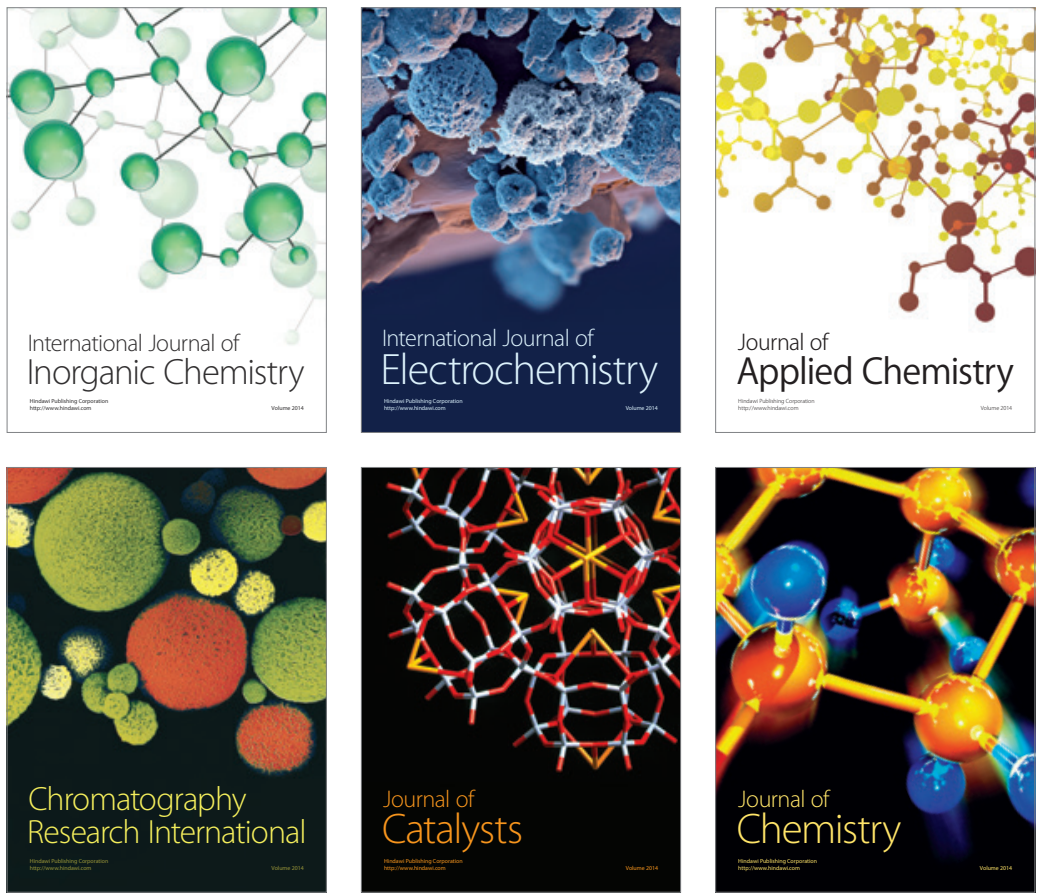

Journal of

Applied Chemistry
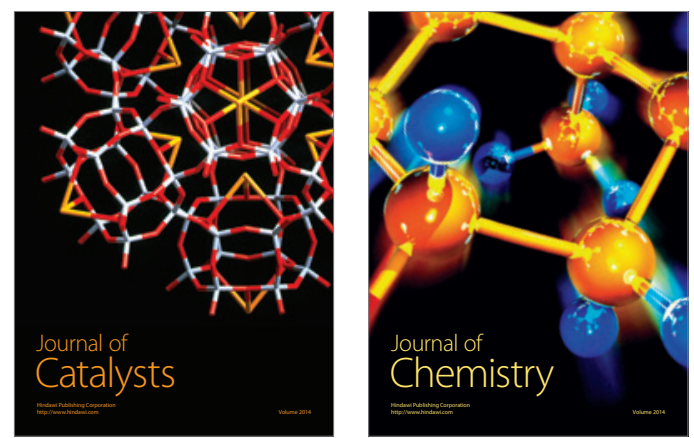
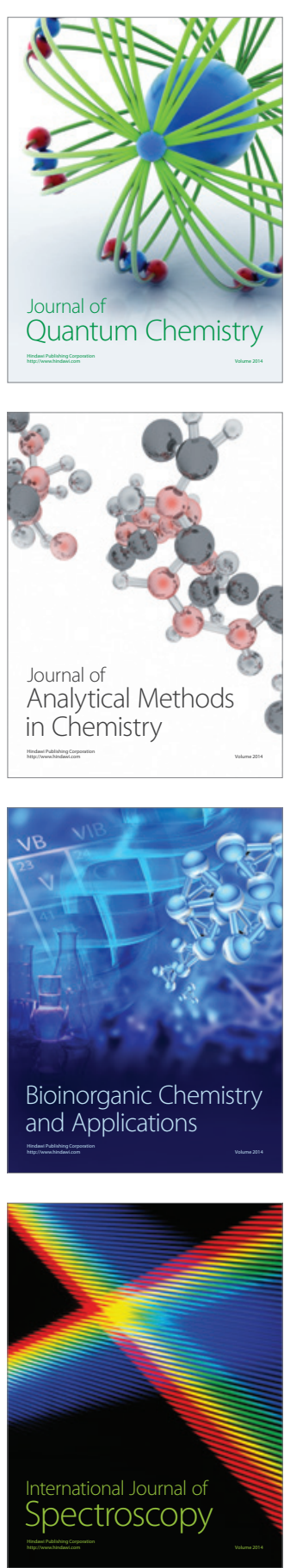